\title{
The Key to Second Language Writing Performance: The Relationship Between Lexical Competence and Writing
}

\author{
İlknur YÜKSEL \\ Eskisehir Osmangazi University, Eskisehir, Turkey
}

\begin{abstract}
Vocabulary knowledge is an important component of the writing skill and it has many dimensions, such as size, depth, and productive, in interaction with writing skill. To evaluate this relation and determine which dimension is the most effective for second language writing quality, the present study was conducted. Turkish EFL (English as a Foreign Language) learners' lexical competence and writing abilities were examined through their vocabulary profiles and academic essays. The results of each vocabulary measure indicated that the participants had a limited vocabulary size, containing words mostly from 2,000 to 3,000 frequency bands and thus, the productive vocabulary knowledge of the participants mostly consisted of $1 \mathrm{k}+2 \mathrm{k}$ words and the use of academic words in their essays was very low. The results of the study revealed that the lexical competence covering the main components of vocabulary knowledge was a good predictor of the students' quality of writing performance.
\end{abstract}

Keywords: lexical competence, L2 writing, academic writing, regression model

\section{Introduction}

The significance of vocabulary knowledge for fluent and accurate language use and for any skill competence, such reading, speaking, and writing has been widely recognized by second language researchers and teachers. Over the last twenty years, much has been done in the field of vocabulary in the context of the acquisition of foreign or second languages (L2). Despite the consensus that vocabulary affects the quality of writing strongly (Cumming, Kantor, Baba, Erdosy, Eouanzoui, \& James, 2005; Munice, 2002), more empirical evidence is required to indicate the possible relationship between vocabulary knowledge and writing quality (Lee, 2003).

Motivated by this neglect in the L2 vocabulary research, this study aims to investigate the relationship between Turkish EFL learners' lexical competence and academic writing performance. To realize this aim, as the first step is to determine detailed description of L2 learners' lexicon through breadth, depth, receptive and productive tests, which compose different dimensions of lexical competence and then to find out whether and which of these dimensions could predict the lexical quality of the learners' academic writing. The rationale of this study is that vocabulary is precondition for academic writing particularly for L2 learners since they have limited vocabulary to transport their knowledge into complex and coherent sentences fluently (Morris \& Cobb, 2004). Thus, the learners should know about their lexical competence profile and its relationship with their writing performance.

İlknur YÜKSEL, assistant professor, Ph.D., Department of ELT, Education Faculty, Eskisehir Osmangazi University. 
The expectation is that the results of such a detailed analysis of lexical competence and writing competence will contribute to second language acquisition research by indicating the incremental nature of vocabulary through the different scores of vocabulary dimensions and investigating writing as multifaceted complex skill. Moreover, for teachers and learners, these results could provide a good guideline for vocabulary development and writing proficiency.

\section{Lexical Competence and Lexical Performance}

To define the mastery of word knowledge, many models have been proposed by the researchers. One of them is separate trait model, which examines lexical knowledge in terms of separate components. According to this perspective, Nation (2001) proposed the list of different kinds of knowledge that a person must master in order to know a word, namely, the meaning(s) of the word, the written and spoken form of the word, the grammatical behavior, the collocations, register, association, and frequency of the word.

Rather than individual properties of words, some researchers opted to examine the learners' general state of the lexicon completely. This global trait model covers the overall state of learners' vocabulary rather than "sub-knowledge" of words such as collocations and semantics. Two dimensional models such as "breadth" and "depth" of vocabulary knowledge or receptive and productive vocabulary (Laufer, 1998; Qian \& Schedl, 2004; Vermeer, 2001; Webb, 2005) or three dimensional models, like the one proposed by Henriksen (1999) were applied in the literature to examine the L2 learners' lexicon and its relationship with other skills.

From this perspective, vocabulary knowledge is widely defined in terms of two sub-dimensions, "breadth" and "depth". Researchers distinguish "breadth" or "size" of knowledge, which can be defined as the number of words of which the learner knows at least some significant aspects of the meaning, from "depth" of knowledge, which refers to the quality of vocabulary knowledge, namely how well a particular word is known (Read, 2004; Qian, 2002; Zarev, Schwanenflugel, \& Nikolova, 2005). Breadth has been usually studied by examining participants' vocabulary size and their knowledge of words from different frequency bands (Laufer, 1998; Laufer \& Nation, 1995; Waring, 1997).

Contrary to the general description of lexicon through vocabulary size tests, the "depth" tests have been used in order to describe the components of lexicon in details. The depth dimension is considered to cover many components such as pronunciation, spelling, meaning, register, frequency, and morphological, syntactic, and collocation properties (Qian, 1999; Qian \& Schedl, 2004; Vermeer, 2001). In addition to these components, Zareva, Schwanenflugel, and Nikolova (2005) claimed that associative behavior could be defined as an indicator of depth knowledge since association or connectivity among words in the L2 lexicon could explain the cognitive and semantic processes in the memory. Association tests are claimed to reveal the learners' associative patterns of meaning connections. Zareva, Schwanenflugel, and Nikolova (2005) tested the L2 learners' depth of vocabulary knowledge through association tests by investigating the number of associations and native-likeness of these associations. With this study, the researchers intended to determine how words are organized in L2 learners' lexicon and whether semantic connections are organized similar to the native speakers. It was a very detailed investigation of depth knowledge.

Although the breadth and depth dimensions are usually defined as separate constructs, Qian (1999) put forth that these components of vocabulary knowledge are structurally and functionally interrelated. He confirmed his 
argument with vocabulary study with 77 Korean and Chinese speakers. Qian (1999) obtained that the scores of vocabulary level tests and word associate test were close, and knowledge of primary word meaning could often include knowledge of synonym, polysemy, and collocations, especially if the words shared these elements in the learners' L1 (first language).

The other dimension that defines vocabulary knowledge is the receptive-productive. In general, L2 researchers agree that there is a difference between vocabulary used for comprehension and vocabulary used for production. Thus, it could be generally defined that being able to understand a word is known as receptive knowledge and is normally connected with listening and reading. To be able to produce a word while speaking or writing is defined as productive knowledge (passive/active). Thus, this dimension has the bridging function between lexical competence and performance (Henriksen, 1999; Laufer, 1998; Schmitt, 2000; Zareva, Schwanenflugel, \& Nikolova, 2005).

Furthermore, it is posed that the receptive-productive dimension is not a dichotomous one but a continuum. In that sense, according to Waring (2002), the receptive knowledge of word comes from the productive and is essentially a requirement of productive words. In other words, it reflects the notion that "one has to meet a word in reception before it can be produced" (Waring, 2002); a word passes a threshold from receptive into productive use. As this continuum and other definitions imply that word comprehension does not automatically predict its use (production). Laufer (1998) acknowledged that mere memorization of a word form in a given context without understanding its meaning cannot be called productive vocabulary. The learners' active involvement into the production activity and use of word in a context is essential for productive vocabulary learning.

Henriksen (1996) has taken this a step further by creating a model of vocabulary acquisition based on development along three continua, the partial-precise continuum, the receptive-productive continuum, and the depth-of-knowledge continuum. Henriksen (1996) agreed on the assumption that language develops long a continuum, or in some kind of hierarchical order and poses that the partial-precise continuum is a knowledge continuum whereby levels of word knowledge are operationalized at different levels of understanding and comprehension. The receptive-productive continuum is a control continuum, which describes at different levels of access and use ability operationalized through different kinds of receptive and productive tasks. Lastly, the depth-of-knowledge continuum entails not only the word's referential meaning, but also the paradigmatic and syntagmatic relationships.

Applying the three-dimensional model proposed by Henriksen (1999) Zareva, Schwanenflugel, and Nikolova (2005) conducted a study to investigate the macro level of lexical competence in association with language proficiency. The macro level of participants' vocabulary knowledge was described with respect to quantity, quality of participants' lexicon, and their metacognitive awareness. Metacognitive awareness was defined as the individuals' ability to monitor and evaluate how much they knew. The results showed that vocabulary size, word frequency effects, and number of associations were more sensitive to language proficiency. Thus, they concluded that quantity and quality (including associations) were much more proficiency-dependent.

Using the collected data, Zareva (2005) tested the three dimensional global trait model of lexical knowledge proposed by Henriksen (1999) in order to determine whether the proposed three dimensions fully capture the overall state of lexical knowledge of the participants and which of the dimension is most revealing the lexical competence. The predictors of the lexical knowledge were described as self-reported vocabulary knowledge, vocabulary size, number of associations, and native-like commonality of associations (i.e., how close to native 
speakers' association), word frequency effects, and number of associations. Zareva (2005) included native speakers in the study like the previous one to evaluate the lexical competence of L2 learners more accurately. The results showed that all variables were highly inter-correlated and there was a significant relationship between participants' actual knowledge of words and five predictors, particularly between the participants' actual and self-reported vocabulary knowledge. When all predictors were analyzed one by one to determine the predictor of lexical knowledge, the smallest "best" set of predictors of vocabulary knowledge was found as a two-predictor model consisting verifiable self-report and vocabulary size. Thus, instead of one predictor of vocabulary knowledge, it was claimed that two predictors would be more efficient. These predictors could account equally well for the proficiency differences and the differences with native speakers. The overall results supported the plausibility of three-dimensional model of Henriksen.

Some studies also analyzed the written products of the students to determine the relationship between these dimensions and writing ability. As an example of such studies Waring (1997) compared the receptive and productive sizes of Japanese learners with a within-subject design study. Applying Receptive Vocabulary Levels test developed by Nation (1990; citied in Nation, 2001) and the Productive vocabulary Levels test (Laufer \& Nation, 1995) with the same words tested, Waring determined the lexical competence of the learners, and then another production task was given. The results of vocabulary tests and vocabulary profiles of written reports were compared. The results confirmed the common assumption that receptive vocabulary was larger than the productive vocabulary.

Laufer (1998) conducted a similar study with the same instruments but investigated the gains in the passive (receptive), controlled free (i.e., sentence-based writing) and free active (production, essay writing) vocabulary in one year instruction. Laufer (1998) divided productive vocabulary into controlled production and free production. This distinction distinguished students' ability to produce a word when required to do so by a teacher or test (controlled) and their actual production while writing on their own. The results indicated that students might not feel confident enough to use the word when writing but instead prefer to another word that is more frequent.

The consensus of the studies on vocabulary knowledge is that students' receptive vocabulary is usually larger than their productive vocabulary. For instance, a learner may recognize the word impede and even be able to provide a synonym when encountering within a context, however, be unable to recall the word while writing (Laufer, 1998; Laufer \& Nation, 1995; Nation, 2001).

When the learners' deficiencies of productive vocabulary has been approved by many studies with different learners at various proficiency levels in different contexts, the productive vocabulary knowledge has started to reach a considerable interest, as well as vocabulary size studies. Laufer and Nation's (1995) study guided many studies on the ways to determine the productive vocabulary levels of the learners by proposing a measure, Lexical Frequency Profile.

Laufer and Nation (1995) used Nation's Range Program, which is also known as Vocabprofle, to produce a Lexical Frequency Profile (LFP) of student compositions. In Laufer and Nation's (1995) study, essays written by 65 learners of differing levels of proficiency in English were examined. The participants were asked to write a 300 word length argumentative essays and the underlying aim of this study was to determine to what extend such a profile would correlate with the students' scores on productive vocabulary level tests. As a result, Laufer and Nation indicated that the LFP measures of learners' compositions could be compared with scores of standard 
vocabulary tests. There was a correlation between performance on vocabulary tests and proportions of low and frequency words in their compositions. The results of this study also validated the LFP as an effective and reliable measure for assessing the productive vocabulary.

According to Laufer and Nation (1995), LFP is a useful diagnostic test that measures free productive vocabulary in the composition discriminating between learners at different proficiency levels. Since the results of LFP correlates with an independent measure of vocabulary knowledge, it is considered as reliable and valid measure of lexical use in writing.

Laufer and Nation (1995)'s study received considerable interest in the vocabulary development research. LFP has been used by many researchers to determine the productive vocabulary use of the learners (Goodfellow, Jones, \& Lamy, 2006; Morris \& Cobb, 2004; Muncie, 2002), As mentioned before, LFP has the potential to compensate the lack of measure of vocabulary use in writing. Muncie (2002) applied LFP to determine the effectiveness of the process writing approach of Japanese students by comparing the learners' performance in a timed compositions and process writing. Depending on the results, in which there was no significant difference of vocabulary use in two writing types, different implications to improve process-writing approach were suggested.

Furthermore, Goodfellow, Jones, and Lamy (2006) used LFP measure as a potential source for automatic feedback for distance learners. They hypothesized that LFP analysis of distance learners' assessment would be useful in a formative way since the learners could learn about the quality of their assessments (i.e., compositions) in terms of vocabulary use. They emphasized that learners' use of vocabulary is an important indicator of the overall quality of their writings. Thus, they investigated whether an LFP measure did correspond to teachers' marks for a group of assignments. The results indicated that LFP has the potential for the considerable improvement if the procedure is repeated. Additionally, Goodfellow, Jones, and Lamy (2006) emphasized that LFP could be an effective self-assessment tool as well.

\section{Second Language Writing Performance}

The findings of the studies on the use of LFP emphasized the significance of writing skill once more. Cumming (1998; citied in McDonough, 2002) defined the writing skill that,

The word writing refers to not only text in written script but also the acts of thinking, composing and encoding language into such text; these acts also necessarily entail discourse interactions within a socio-cultural context. Writing is text, composing, and is social interaction. (p. 61)

As this definition implies, there are many factors and components of writing, vocabulary is one of them and perhaps the most important one. Henriksen (1999) emphasized the importance of converting learners' receptive vocabulary into productive vocabulary by getting learners actively use recognized and new words. In this respect, Lee (2003) investigated to what extend receptive vocabulary could become productive after explicit vocabulary instruction. While examining the vocabulary use in writing of 65 secondary school students at intermediate level from different L1 backgrounds, he integrated reading, writing, and vocabulary instruction. The results confirmed that explicit and systematic vocabulary instruction helps learners convert receptive vocabulary into productive vocabulary in an immediate writing task. Munice (2002) suggested that through writing productive vocabulary use improves better than speaking since more sources are available such as dictionary, books; also the learners have more time to think, plan, and revise. 
However, writing skill is considered as problematic for L2 learners. Native speakers of English learn new words all their lives through interaction with other speakers and exposure to the language in formal and informal situations, but L2 learners' exposure to and use of the target language is often limited (Kaur \& Hegelheimer, 2005). The limited vocabulary makes writing more difficult. Moreover, formal writing especially in an academic setting requires L2 learners to have a strong linguistic foundation, including a vast range of lexical skills because it requires transforming knowledge; L2 learners have to be aware of how to process information and transfer it by using effective vocabulary. Therefore, if these learners do not have a broad range of productive vocabulary knowledge, they cannot produce the types of writings expected of them in an academic setting (Kaur \& Hegelmeir, 2005).

In the field of vocabulary development, it has started to be realized that vocabulary proficiency is a good predictor of writing quality (Lee, 2003; Munice, 2002; Reid, 1993; Schmitt, 2000). For instance, Cumming, Kantor, Baba, Erdosy, Eouanzoui, \& James (2005) found that lexical sophistication, which was analyzed through average word length and type and token ratio, was an important factor for the quality of writing in TOEFL exams. Therefore, examining the lexical competence of the learners is also crucial to assess their writing performance.

Particularly, while teaching writing, many teachers used to concentrate on the grammatical well-formedness of a composition. However, it has been approved that vocabulary is quite important for writing performance (Nation, 1994; Schmitt, 2000). Schmitt (2000) defined the other typical problem that L2 learners encounter while writing as the use of basic, high frequent words. This influenced the quality of L2 learners since the learners expressed their thoughts in simpler and incoherent sentences. Thus, the L2 learners' writing performance tend to be far from native-like performance since good native speaking writers would use more precise lower-frequency words while writing (Schmitt, 2000, p. 155).

In the literature, different measures of lexical competence have been repeatedly proved to correlate with overall writing quality (e.g., Cumming, Kantor, Baba, Erdosy, Eouanzoui, \& James, 2005; Laufer \& Nation, 1995). In this study; a three-dimensional model would be used to determine the lexical competence of the participants and to examine the potential of this model to account for the participants' writing proficiency. It should be underlined that a model here means a set of predictor of L2 learners' lexical competence. Thus, the analysis in this paper is predictive in nature and intends to determine the best set of predictors of lexical competence and writing performance, as Zareva (2005) conducted in his study.

\section{Method}

The present study was designed as a quantitative study on the purpose of describing the Turkish EFL learners' lexical competence and writing performance and revealing the relationship between these two basic language skills. Through correlation analysis and regression models, the best predictor for writing performance for EFL students in Turkish context was examined.

\section{Aim and Research Question}

The aim of this study is to investigate the relationship between Turkish EFL learners' lexical competence and academic writing performance. Addressing to this aim, the following research questions were asked:

(1) Does learners' lexical competence relate with their writing performance?

(2) Do the components of lexical competence correlate with each other? 
(3) What is the best predictor of lexical competence and writing performance?

\section{Participants}

Forty Turkish EFL learners enrolled in Education Faculty in Turkey participated in this study through probability sampling technique. The students enrolled in Advanced Reading and Writing courses were asked to participate to the study voluntarily. All participants were adult L2 learners, attending to English Language Teaching program. The participants were admitted into their programs on the basis of their language scores at the university entrance exam. Thus, it could be assumed that the proficiency levels of the participants are upper-intermediate and advanced.

\section{Instruments}

Since vocabulary knowledge is not an all-or-nothing phenomenon and since no single test combining both vocabulary size and depth is available, "multiple test approach", proposed by Laufer (1998) as well, was used in this study. Using a battery of tests, each test measured a different aspect of vocabulary knowledge. Laufer (1998) explained the advantages of "multiple test approach" that the results of all tests can provide a comprehensive picture of learners' vocabulary at different stages of language development, and by comparing the results of each participant the relationship among different aspects of lexical knowledge in the same learners could be detected. The instruments were adopted from the web site of Cobb (2004) since they were used and validated by many studies (e.g., Horst, Cobb, \& Nicolae, 2005).

\section{Vocabulary Level Test}

As emphasized before, vocabulary size is considered as significant for writing and academic success. Considering the results of the previous studies on vocabulary size tests (e.g., Laufer, Elder, Hill, \& Congdon, 2004), the Vocabulary Level Test was used in the present study to find out the overall state of the learners' vocabulary.

In this test, the learner is required to match groups of three words out of six with their paraphrases. This test consists of items from the 2,000 most frequent vocabulary, the 3rd thousand, the 5th, the 10th thousand and Academic Vocabulary (AWL). The target words are tested in isolation so that no contextual clues are provided. Each frequency level consists of 30 items at five sections. The answers are scored as correct and incorrect; each correct answer is given one-point, and thus the maximum score is 150 .

The Academic Word List consists of 570 word families that are frequency and wide ranging in academic texts. It was created by Coxhead (2000) by counting the frequency, range, and spread of the word forms in a specially constructed academic corpus, such as the university divisions of Humanities, Science, Commerce, and Law (Ming-Tzu \& Nation, 2004).

\section{Word Associate Test}

This test was designed by Read (1998; citied in Cobb, 2004) to assess how well the learners know the word. This test includes adjectives commonly used in English. There are 40 items and eight distracters for each item. The distracters were arranged in two boxes, left and right. The words on the left are the other adjectives that could help students explain the target item. In the right box, there are nouns that may come after the target item in a phrase or sentence. For two boxes, the students are asked to select four words that they think relevant to the stimulus word. The distribution of the correct answers through boxes can change as two in the right and two in the left or one in 
the right and three in the right. There are different combinations to decrease the guessing and chance factor.

\section{TOEFL Writing Sub-test}

For academic writing task, one of the dependent writing task of TOEFL exam was chosen since these prompts have been asked to a large population, and these tasks are considered as valid and reliable. For the independent essays in this study, an instruction for the participants is:

"Read the question below. You have 30 minutes to plan, write, and revise your essay. Typically an effective response will contain 300 words".

The writing prompt, which was taken from TOEFL exam conducted in 2004, is:

"Schools should allow students evaluate teachers. Do you agree or disagree? Use specific reasons and examples to support your opinion".

Each essay was rated holistically by two raters following the Independent Writing Task Scoring Guidelines adapted from Cumming, Kantor, Baba, Erdosy, Eouanzoui, and James (2005). The final score or writing quality rating was calculated by the means of two raters' ratings for that essay.

\section{Vocabprofile}

In this study, vocabulary profiler, which is available on www.lextutor.ca/ was used to measure the learners' lexical use (i.e., productive vocabulary) in writing. As discussed in the background of the study above, LFP has been applied by many studies in different context with different proficiency groups (Cobb, 2004; Laufer \& Nation, 1995; Morris \& Cobb, 2004) and defined as reliable and valid instrument. Besides, LFP has different advantages over other instruments measuring productive vocabulary, it gives a detailed picture of lexical richness, using the three frequency levels rather than the more simpler "frequent" and "sophisticated" levels (Laufer \& Nation, 1995). Moreover, it can discriminate the learners who use "frequent" and less frequent words instead of the ones that vary their limited vocabulary (Morris \& Cobb, 2004; Muncie, 2002). Thus, the findings of LFP could reveal the productive side of lexical competence effectively.

To operate the LFP test, Vocabprofile, a text is typed into the computer program and text analysis, consisting of the percentages of type/token ratio and word families supplied according to four frequency levels, according to $1 \mathrm{k}$ (1 to 1000), 2k (1001 to 2000), off-list and AWL words (Cobb, 2004).

In this study, the learners' essays that they write at TOEFL writing sub-test were analyzed by Vocabprofile. According to Laufer and Nation (1995), 300 word length is sufficient to have an efficient analysis, although the writing task requires students to write 300 words; considering the longer ones, 300 words of each student's essay were entered. Before typing the essays into computer program, the words spelled incorrectly were cleaned up to find out the learners' productive vocabulary used correctly. Additionally, off-list words were determined with raters by examining the essays.

In all these tests, a "word" is defined as a base form with its inflected and derived forms, which means word families.

\section{Data Analysis}

After the vocabulary tests were scored and the participants' argumentative essays were analyzed through Vocabprofile, they were graded by an independent researcher. The results of each vocabulary test and the ratio of $1 \mathrm{k}$ and $2 \mathrm{k}$ words and AWL were analyzed together to obtain the score of lexical competence of the participants in 
order to investigate whether the lexical competence of each participant correlated with their writing scores or not.

To answer the research questions and to examine the correlation among the variables, Pearson correlation test was first conducted and then multiple and simple regression analysis, which was commonly employed for relationship and predictive purposes, was used as a statistical procedure. Creswell (2009) defined the regression analyses as the study of "best fit" that indicates the variance of one variable from another. In this respect, the criterion variable was participants' TOEFL writing performance (scores). In this context, the predictor variables were (1) word association test scores (for depth of vocabulary knowledge); (2) the type/token ratio analysis of LFP (for productive vocabulary); (3) the scores of the Vocabulary Level Test. Through these correlation analyses, it was aimed to reveal the relationship between the writing skill and lexical knowledge, besides to determine the predictive dimension of lexical competence for the writing performance.

\section{Results}

\section{Lexical Competence}

In this study, referring to Zareva (2005)'s study, in which Henriksen (1999)'s three-dimensional global trail model of lexical knowledge was tested, the participants' lexical competence were defined with the combination of scores of vocabulary size, word association and productive vocabulary, which included the ratios of $1 \mathrm{k}+2 \mathrm{k}$ and AWL. These dimensions of vocabulary were analyzed as predictor variables to test whether any of them or any combination of them could predict the participants' writing proficiency.

Although the focus of this study was not the participants' performances on the vocabulary tests and their vocabulary profiles of the essays, the analyses of each component were conducted so that discussion on the results of relationship between the components of lexical competence and writing might be in more meaningful perspective.

Thus, the descriptive statistics of scores at the vocabulary level test and word association tests showed that, Table 1

The Descriptive Statistics of Vocabulary Size and Word Association

\begin{tabular}{lllll}
\hline & Min. & Max. & Mean & SD \\
\hline Vocabulary size & 47.78 & 88.89 & 75.41 & 7.58564 \\
Word association & 41.88 & 76.88 & 66 & 9.972657 \\
\hline
\end{tabular}

The mean value of the participants' vocabulary size was 75.41 with the minimum score of 47.78 and maximum score of 88.89 . When the different frequency levels of the words in the test of vocabulary level, which was administered to find out the vocabulary size of the participants, was analyzed, the results were illustrated in the following Table 2:

Table 2

The Distribution of the Scores of Vocabulary Level Test

\begin{tabular}{lllll}
\hline & Min. & Max. & Mean & SD \\
\hline 2,000 level & 13.00 & 18.00 & 16.25 & 1.42775 \\
3,000 level & 11.00 & 18.00 & 16.58 & 1.53402 \\
5,000 level & 8.00 & 18.00 & 15.02 & 2.20125 \\
UWL & 9.00 & 18.00 & 14.20 & 2.05314 \\
10,000 level & .00 & 14.00 & 7.65 & 3.17482 \\
\hline
\end{tabular}


The participants did better in the 3,000 level words with the mean value of 16.58 as well as in the 2,000 level words with the mean value of 16.25 , while the participants did worst in the 10,000 level words since it had the mean value of 7.65. Thus, it could be suggested the participants was good at the high frequent words while they failed to recognize the least frequent words at the UWL and 10,000 level. Considering the proficiency levels of the participants, assumed to be advanced as university students in the ELT department, the results of vocabulary sizes were surprising.

The other component of the lexical competence taken into account in this study was the depth of vocabulary knowledge. This was measured by a word association test, and the results, shown in the table above, indicated that the mean of success of all participants was 66.00 with minimum score, 42 and 77 out of 100 . Considering these values, it could be interpreted that the students were not so good at word association test. Their depth of vocabulary knowledge seemed not as developed as their size of vocabulary.

The last dimension or component of lexical competence was the productive vocabulary, which referred to the vocabulary that the participants used while writing their essays. As explained before, to find out the participants' productive vocabulary, their argumentative essays were analyzed with Vocabprofile and the ratios of $1 \mathrm{k}+2 \mathrm{k}$, AWL words, lexical densities of the essays and the percentage of function and content word uses were determined. The two high frequency categories (words in the 1-1,000 and 1,001-2,000 most frequent bands) were taken together to describe the use of high frequent words. Furthermore, to have the equal analysis, 250 words of their essays for each participant were entered into the program of Vocabprofile.

For all participants, the descriptive statistics were obtained to give the profile of the participants' productive vocabulary and given in Table 3:

Table 3

The Productive Vocabulary Profiles for All Participants

\begin{tabular}{lllll}
\hline & Min. & Max. & Mean & SD \\
\hline $1 \mathrm{k}+2 \mathrm{k}$ & 88.14 & 96.85 & 92.68 & 7.67000 \\
AWL & 1.56 & 9.60 & 5.42 & 1.76000 \\
Function words & 45.82 & 60.40 & 53.40 & 3.77884 \\
Content words & 29.60 & 43.03 & 35.56 & 3.33888 \\
Lexical density & .40 & .54 & .46 & .03816 \\
Anglo-Sax & 65.99 & 81.25 & 75.22 & 3.49594 \\
\hline
\end{tabular}

The percentage of the use of $1 \mathrm{k}$, which refers to 1,000 level words, and of $2 \mathrm{k}$, for 2,000 level words was higher than AWL words. $92.68 \%$ of the words in all participants' essays belonged to the 2,000 and 3,000 word levels, which were high frequent words (Laufer \& Nation, 1995). On the other hand, only $5.42 \%$ of the words in the essays were from academic word list. Thus, it could be interpreted that the productive vocabulary of the participants mostly consisted of high frequent words, and their levels of academic word use was not so advanced.

In that sense, when the use of function and content words was explored further to have an idea of the lexical density of the participants' essays, it was seen that function words were used more (mean $=53.40$ ) than content words (mean $=35.56$ ). Thus, the mean of lexical density of the essays, including content words, was $40 \%$.

Furthermore, the LFP analysis pointed to an interesting finding that out of the tokens in the participants' 
essays, Anglo-Saxon words were used at $75.22 \%$.

The general picture emerging from this analysis was that L2 learners in this study had a limited vocabulary size and depth knowledge considering their assumed proficiency levels. Additionally, the profiles of their productive vocabulary in their essays indicated that they mostly used high frequent words at 1,000 and 2,000 frequency levels and more function words than content word, thus their lexical density was also limited (40\%).

\section{Correlation Between Lexical Competence and Writing}

In order to answer the first research question, which was asked to determine whether the lexical competence associated with the writing scores of the participants or not, the scores on each dimension of vocabulary knowledge such as size of vocabulary knowledge, depth of vocabulary knowledge, and productive knowledge were taken together as a common score for lexical competence and put into correlation analysis with the writing scores. The correlation analysis was employed with Pearson product-moment analysis.

The results pointed out that lexical competence was significantly correlated with the writing scores at the reliability level of 0.01 since the coefficient value of correlation was equal to .548 .

Considering this significant relationship between lexical competence and writing proficiency, a simple linear regression analysis was conducted to explore further whether the lexical competence could predict the writing. In the regression analyses, firstly the significance of the model (either simple or multiple), then the coefficient values of beta and the values of $R^{2}$ and $A d j . R^{2}$ should be mentioned to ensure the appropriateness of the model for the prediction. In the simple regression analysis with the lexical competence as predictor variable and writing as a criterion variable, the significance level of this regression model was found as $F=16,315, P$ $=.000<0,05$ thus it could be suggested that this model was statistically appropriate. Then, the results indicated that,

Table 4

The Results of Regression Analysis Between Lexical Competence and Writing (Criterion Variable: Writing)

\begin{tabular}{lllllll}
\hline No. of predictors & Regressor subset & Beta & P & R & R square & Adjusted R square \\
\hline 1 & Lexical competence & .807 & $<0.05$ & .548 & .300 & .282 \\
\hline
\end{tabular}

The beta coefficient value of lexical competence (.807) was statistically significant since $P<0.05$. In addition, according to the values of $R^{2}=.300$ and $A d j . R^{2}=.282$, it could be suggested that lexical competence could predict the participants' writing proficiency. In other words, lexical competence including size, depth, and productive vocabulary are related to the writing proficiency and the participants' knowledge on these dimensions of lexical competence could explain their writing performance.

These findings invited for further investigation whether the components, dimensions, of lexical competence correlate with each other and which of them could best predict the writing scores. Thus, the bivariate relationships between the variables, namely size, depth of vocabulary knowledge, and productive vocabulary including the ratios of $1 \mathrm{k}+2 \mathrm{k}$ and AWL, were all analyzed by employing Pearson product-moment correlation, again. First of all, the distribution of the scores on the variables was examined by Kolmogorov-Smirnov test and found to be normal. Then, the results of correlation analyses were obtained, as shown in the correlation matrix below. 
Table 5

Correlation Matrix Between Components of Lexical Competence and Writing Proficiency

\begin{tabular}{llllll}
\hline & Writing & Size & Word association & $1 \mathrm{k}+2 \mathrm{k}$ & AWL \\
\hline Writing & 1 & $.401^{*}$ & $.566^{* *}$ & .070 & .022 \\
Vocabulary size & $.401^{*}$ & 1 & $.505^{* *}$ & .009 & .002 \\
Word association & $.566^{* *}$ & $.505^{* *}$ & 1 & .014 & .059 \\
$1 \mathrm{k}+2 \mathrm{k}$ & .070 &, 009 & .014 & 1 & $-.796^{* *}$ \\
AWL & .022 & .002 & .059 & $-.796^{* *}$ & 1 \\
\hline
\end{tabular}

Notes. * Correlation is significant at the level of the 0.05 level. ${ }^{* *}$ Correlation is significant at the level of 0.01 .

As the table illustrated, it was obvious that there were statistically significant correlations between writing scores and size of vocabulary knowledge at the reliability level of 0.05 , also between writing scores and depth of vocabulary knowledge at the reliability level of 0.01 . On the other hand, it was observed that the coefficient value of the correlation between writing scores and depth knowledge was higher than the value of the correlation between writing scores and size. Thus, it could be interpreted that the scores of word associate tests are more correlated with writing proficiency than with the scores of vocabulary level test.

Furthermore, it was found that the ratios of $1 \mathrm{k}+2 \mathrm{k}$ and AWL, which represented the productive vocabulary, were found not to be correlated with the writing scores. In addition it was obtained that these variables were not correlated with other variables, except correlating with each other negatively. In other words, when $1 \mathrm{k}+2 \mathrm{k}$ words were used more in writing, the ratio of AWL words was decreased.

Since both depth and size of vocabulary knowledge were found to be significantly correlated with writing separately, to investigate further which of these variables was statistically the "best" predictor of the writing proficiency a simple linear regression analysis for each variable and multiple linear regression analysis with the combination of two predictors, namely size and depth, were employed.

Firstly, a simple linear regression was conducted to find out whether either of them could predict the writing scores. The results of simple regression analyses for depth and size of vocabulary knowledge with writing scores individually were presented in the table below:

Table 6

The Summary of Regression Analyses of Size and Depth With Writing

\begin{tabular}{lllllll}
\hline No. of predictors & Regressor subset & Beta & P & R & R square & Adjusted R square \\
\hline 1 & Size & .305 & $<0.05$ & .401 & .161 & .139 \\
1 & Depth & .559 & $<0.05$ & .566 & .320 & .302 \\
\hline
\end{tabular}

The results of the regression analysis with size of vocabulary knowledge as predictor variable and writing as criterion pointed out that $F=7.293, P=.010<0.05$ so the regression model for these variables are statistically significant. Then, considering the output of the regression analysis in the Table 6 above, it could be suggested that size of vocabulary knowledge could virtually predict the writing scores since the coefficient values of beta (.305) were found to be statistically significant since $P<0.05$.

On the other hand, the depth of vocabulary knowledge was analyzed with a simple linear regression analysis it was again found that there was significant relationship between depth of vocabulary knowledge and the writing scores so this analysis was statistically significant $(F=17.906, P=.000<0.05)$. According to the coefficient 
values of beta (.559) were found to be statistically significant since $P<0.05$ and $R^{2}=.566$ and $\mathrm{Adj} . R^{2}=.302$, it could be suggested that depth of vocabulary knowledge as a predictor variable could explain the writing scores significantly.

To sum up, as illustrated in the table, both variables could predict the writing scores one by one, however considering $R^{2}$ of the values, it was obvious that the depth of vocabulary knowledge seemed to be a stronger predictor since $R_{(\text {depth })}^{2}=.320>R_{(\text {size })}^{2}=.161$.

In that context, a multiple regression analysis was conducted with these two predictor variables (i.e., size and depth of vocabulary knowledge) and criterion variable (i.e., writing scores). They were all entered into regression simultaneously. When they were analyzed, the obtained significance level of this regression model was $P=.000<0.05$, however considering the value of $R^{2}$ and other coefficient values were presented in the Table 7 below.

Table 7

Two-Predictor Model Criterion (Variable: Writing)

\begin{tabular}{lllllll}
\hline No. of predictors & Regressor subset & Beta & P & R & R square & Adjusted R square \\
\hline \multirow{2}{*}{2} & Size & .118 & $>0.05$ & & & \\
& Word associate (depth) & .482 & $<0.05$ & .582 & .338 & .302 \\
\hline
\end{tabular}

It was found that as the beta coefficient value of size of vocabulary knowledge (.118) was not statistically significant since $P>0.05$, this regression model with the combination of size and depth of vocabulary was found not to be appropriate to predict the writing scores of the participants. Moreover, two-predictor model with the combination of size and depth of vocabulary knowledge was found as not significant as the one-predictor model in which each predictor variable was correlated individually with the writing scores before. Thus, it could be interpreted that the combination of both size and depth of vocabulary scores could not predict the participants' writing proficiency.

To sum up, the results of Pearson product-moment correlation analyses pointed to statistically significant relationship between both the size of vocabulary knowledge and writing scores and between the depth of vocabulary knowledge and writing scores. The other variables, the ratio of $1 \mathrm{k}+2 \mathrm{k}$ and AWL, which represented the productive vocabulary scores of the participants, were found to be correlated with neither other variables nor with the writing scores. In addition, considering the correlation of size and depth knowledge as predictor variables, simple linear regression analysis was employed for each predictor with the writing scores. The results explained that both variables could predict the writing scores significantly, on the other hand, when these two predictors were analyzed with a multiple linear regression analysis to determine whether the combination of size and depth could also predict the writing proficiency, it was surprisingly found that the combination could not significantly predict the writing proficiency.

It could be concluded that there was a significant relationship between lexical competence and writing proficiency and the lexical competence was found to be able to predict the writing proficiency of the participants. Among the components of lexical competence, size and depth of vocabulary knowledge was found to be correlated with writing scores and when analyzed; it was obtained that the size of vocabulary knowledge and depth of vocabulary knowledge could predict the writing proficiency separately; however, the combination of these two dimensions of vocabulary knowledge could not significantly predict the writing scores. 


\section{Discussion}

The study presented in this paper was conducted within the theoretical framework of the three global-trait model of lexical knowledge, which was proposed by Henriksen (1999) and which was tested by Zareva (2005). Each dimension, size of vocabulary knowledge, depth of vocabulary knowledge, and productive vocabulary, was examined together to gain insight about the lexical competence of the participants.

Before examining the relationship between the participants' lexical competence and writing performance, the profiles of vocabulary knowledge were defined for all participants, taking account the scores of each vocabulary measure. The rationale of these analyses was to gain better insights of the participants' lexical competence so that the following analyses about the correlation between lexical competence and writing could be seen in a better perspective. However, it should be emphasized that the analyses of each measure was only descriptive since the participants of this study constituted a homogeneous group, it could be misleading to judge the participants' scores as good or bad, rather the results of lexical competence profiles would be discussed considering the general assumption in the literature.

Firstly, when all participants' performance at the vocabulary level test was analyzed, it was found that the mean rating of the vocabulary size was $75.41 \%$ (out of 100 ). Among the frequency bands in this test, the participants did better with the words in 2,000 and 3,000 word levels. Considering these results, it could be suggested that the participants had a limited vocabulary size and their vocabulary knowledge mostly consisted of high frequent words. As Nation (2001) underlined for the learners who are in academic studies like university students should have a repertoire with more low frequent words. In addition, in the literature, it was stated that the first 1,000 and 2,000 words are acquired at the early stages and the students should have vocabulary knowledge including 5,000 and academic words in the advanced levels due to the exposure to the words in different contexts (Read, 2004; Schmitt, 2000). However, the results of this study revealed that the participants' receptive knowledge, referring to the vocabulary size, was not as developed as expected.

The results of the word association test lead similar results; the participants' depth of vocabulary knowledge was again limited. This result could be explained due to limited deeper processing abilities of the participants. The participants seemed to have a limited capacity to process the word with its associations and connectivity with other words in their lexicon. Thus, considering Zareva's (2005) claim about the relationship between size and depth knowledge, it could assumed that due to limited vocabulary size, the associate patterns of meaning connections seemed weak for the participants of the study.

Furthermore, the participants' essays were analyzed through Vocabprofile to determine how the participants transferred their breadth and depth of vocabulary knowledge into productive vocabulary, the results of LFP ratios for the productive vocabulary of the participants indicated that the participants used the $1 \mathrm{k}+2 \mathrm{k}$ words $(92.67 \%)$ more than academic words $(5.42 \%)$. In other words, the participants used the high frequent words more than academic words while writing argumentative essays. One of its reasons could be the participants' limited vocabulary size that was determined by the vocabulary level test. Due to limited vocabulary size, the participants could not access to academic words easily so they preferred to express their ideas with most frequent words and as a result, the lexical density of their essays was also low as obtained $0 . .46 \%$, which means the participants used the same words and they could not vary their vocabulary using different patterns. The higher ratio of the function 
word use could be the reason of the low lexical density; the learners did not vary their content words in their essays. This could be interpreted again due to limited vocabulary size.

Moreover, when the tokens in the participants' essays were analyzed in detail, it was observed that the words with Anglo-Saxon origin were mostly used. This could be explained that since the most of the words in the participants' essays belonged to $1 \mathrm{k}+2 \mathrm{k}$ frequency categories, it was expectable that the ratio of Anglo-Saxon words would be higher (75.22\%). As Horst, Cobb, and Nicolae (2005) pointed out that many of the most common English words are of Anglo-Saxon origin.

When the participants' lexical competence of profiles were described, to realize the major aim of this study, the lexical competence with combination of all measures was put into correlation analysis with the participants' writing scores to find out whether the framework of lexical competence was related with the participants' writing proficiency. The results confirmed that the lexical competence was related to the writing proficiency and according to regression analysis, it was statistically indicated that the lexical competence combining different dimensions of vocabulary knowledge (i.e., size, depth, and productive knowledge) could predict the participants' writing proficiency. This finding was consistent with the general assumption in the literature that lexical knowledge including size, depth and productive knowledge is contributory factor for the quality of learners' writing (e.g., Lee, 2003; Munice, 2002). In the literature, particularly, the breadth and depth of learners' vocabulary are claimed to have a direct influence upon the descriptiveness, accuracy and quality of their writing (e.g., Schawna, 2000).

To explain this assumption in detail, the dimensions, namely size, depth of vocabulary knowledge, and productive vocabulary were analyzed to find out whether they were correlated individually with the writing score. According to the results of correlation analyses, depth and size of vocabulary knowledge were found to be correlated with the writing scores separately. While the subcomponents of productive vocabulary, the ratios of $1 \mathrm{k}$ $+2 \mathrm{k}$ for the high frequent words and AWL in the participants' essays were found not to be correlated with their writing scores.

These results were consistent with the assumptions about the "incremental nature of vocabulary knowledge", which posits that not all aspects of the vocabulary knowledge develops at the same pace and the increase in the vocabulary size does not mean that learners will necessarily choose to use these words in their writing (Laufer, 2005; Schmitt, 2000; Waring, 2002). The incremental nature of vocabulary knowledge underlines the fact that the vocabulary knowledge has degrees of knowledge so the lexical knowledge is not an all-or-nothing phenomenon. The one's competence at one dimension of lexical knowledge does not ensure his performance in other dimensions. Thus, it could be suggested that the participants did not transfer their vocabulary size to their productive vocabulary knowledge in their essays in this study. In other words, it could be assumed that the participants' vocabulary size was not directly related to productive vocabulary in their essays since it was possible that the participants might not demonstrate their knowledge of the 5,000 and UWL words, which were found as (mean $=15.05)$ and (mean $=14.02)$ respectively in the analysis of vocabulary level test, in their writing or they were not competent enough with these words to use them appropriately while writing.

Considering this, it seemed plausible to assess the learners' lexical competence as a combination of size, depth, and productive knowledge because taking account of only one dimension for example, to assess writing ability could be misleading since the other vocabulary dimensions could be developed more and they could be more related with writing performance 
Furthermore, in the correlation analyses, negative correlation between $1 \mathrm{k}+2 \mathrm{k}$ and AWL was obtained, which could be interpreted that the more words in the AWL are used, the less $1 \mathrm{k}+2 \mathrm{k}$, high frequent words are used. In the case of increase in the AWL, it could be expected that the learners could prefer to use academic words instead of high frequent words to increase the lexical density and to improve the quality of their writing.

Then, to find out the 'best' predictor of the writing, considering the findings about the correlation between size and writing and depth and writing separately, further analysis was conducted to determine whether they could predict the writing proficiency of the students. Thus, simple linear regression analyses with each predictor variable (i.e., size and depth knowledge) were conducted and it was found that both size and depth could predict writing proficiency individually while depth of vocabulary knowledge was found to be a stronger predictor. When the combination of the depth and size as predictor variables were analyzed with the writing scores through multiple regression models, the results interestingly pointed that the combination could not predict the writing scores significantly.

These results revealed the great potential of depth of vocabulary knowledge. As Read (2004) stated word associations could indicate the vocabulary knowledge more effectively than the other conventional tests of word meaning. The measure of word association could explain the cognitive and deeper processing of vocabulary knowledge which is also activated in writing. The learners' competence of associating words in their lexicon also influences their writing performance. Thus, it could be speculated that associative test measures, namely word association test, to investigate depth of vocabulary knowledge is a valid measures of L2 lexical knowledge and their results relate with the learners' writing performance and the quality of their products. On the other hand, it should underline that depth of knowledge is also strictly related to the breadth of vocabulary (Zareva, 2005), thus further study on the relation between depth and size knowledge could contribute to this field a lot.

\section{Conclusion}

In this study, the three-dimensional model of lexical competence was evaluated in relation with the university students' writing performance. The results revealed that this model could effectively explain the overall state of the learners' lexical knowledge. Additionally, it was indicated that lexical competence as a whole was related with writing performance and it could predict the writing proficiency of the learners. As the "best" predictors of writing performance were size and depth.

In detail, the results on the vocabulary dimensions indicated that the participants' vocabulary size was limited and it mostly consisted of high frequent words. Likewise, the participants' depth of vocabulary knowledge was found as restricted. This limited receptive vocabulary knowledge (i.e., size and depth) was found as correlated with the limited productive vocabulary knowledge as a result of lexical density analysis of participants' writings. In other words, since the participants have limited vocabulary size and depth knowledge, they mostly use high frequent and limited vocabulary while writing.

To conclude, this study showed that the lexical competence and writing performance are correlated and lexical competence covering size, depth, and productive vocabulary knowledge is the key to writing performance; it could predict writing proficiency.

\section{References}

Cobb, T. (2004). The compleat lexical tutor (Vol. 4). TESL-EJ, 8(3), 1-9. 
Creswell, J. W. (2009). Educational research: Planning, conducting, and evaluation quantitative and qualitative research (2nd ed.). Upper Saddle River, NJ: Pearson.

Cumming, A., Kantor, R., Baba, K., Erdosy, U., Eouanzoui, K., \& James, M. (2005). Differences in written discourse in independent and integrated prototype tasks for next generation TOEFL. Assessing Writing, 10, 5-43.

Coxhead, A. (2000). A new academic word list. TESOL Quarterly, 34(2), 213-238.

Goodfellow, R., Jones, G., \& Lamy, M. (2006). Assessing learners' text using the lexical frequency profile. Retrieved from www.er.uqam.ca/nobel/r21270/

Henriksen, B. (1999). Three dimensions of vocabulary development. SSLA, 21, 303-317.

Horst, M., Cobb, T., \& Nicolae, I. (2005). Expanding academic vocabulary with an interactive on-line database. Language Learning \& Technology, 9(2), 90-110.

Laufer, B., \& Nation, P. (1995). Vocabulary size and use: Lexical richness in L2 written production. Applied Linguistics, 16, 307-322.

Laufer, B. (1998). The development of passive and active vocabulary in a second language: Same or different? Applied Linguistics, $19(2), 255-271$.

Laufer, B., Elder, C., Hill, K., \& Congdon, P. (2004). Size and strength: Do we need both to measure vocabulary knowledge? Language Testing, 21(2), 202-226.

Lee, S. H. (2003). ESL learners' vocabulary use in writing and the effects of explicit vocabulary instruction. System, 31(4), 537-561.

Nation, P. (1994). New ways in teaching vocabulary. USA: TESOL.

Nation, P. (2001). Learning vocabulary in another language. Cambridge: CUP.

Nation, P. (2005). Teaching vocabulary. Retrieved from www.asian-efl-journal.com/sept_05_pn.pdf

Kaur, J., \& Hegelheimer, V. (2005). ESL students' use of concordance in the transfer of academic word knowledge: An explanatory study. Computer Assisted Language Learning, 18(4), 287-310.

McDonough, S. (2002). Applied linguistics in language education. London: Arnold Publishing.

Ming-Tzu, K. W., \& Nation, P. (2004). Word meaning in Academic English: Homography in the academic word list. Applied Linguistics, 25(3), 291-314.

Morris, L., \& Cobb, T. (2004). Vocabulary profiles as predictors of the academic performance of teaching English as a second language trainees. System, 32, 75-87.

Muncie, J. (2002). Process writing and vocabulary development: Comparing lexical frequency profiles across drafts. System, 30 , 225-235.

Read, J. (2004). Plumbing the depths: How should the construct of vocabulary knowledge be defined? In P. Bogaards and B. Laufer (Eds.), Vocabulary in a second language, selection, acquisition, and testing (pp. 209-229). Amsterdam: John Benjamins.

Reid, J. M. (1993). Teaching ESL writing. USA: Parentice Hall.

Qian, D. (1999). Assessing the roles of depth and breadth of vocabulary knowledge in reading comprehension. Canadian Modern Language Review, 56, 282-308.

Qian, D. (2002). Investigating the relationship between vocabulary knowledge and academic reading performance: An assessment perspective. Language Learning, 53(3), 513-536.

Qian, D., \& Schedl, M. (2004). Evaluation of an in-depth vocabulary knowledge measure for assessing reading performance. Language Testing, 21, 28-52.

Schmitt, N. (2000). Vocabulary in language teaching. Cambridge: CUP.

Zareva, A. (2005). Models of lexical knowledge assessment of second language learners of English at higher levels of language proficiency. System, 33, 547-562.

Zareva, A., Schwanenflugel, P., \& Nikolova, Y. (2005). Relationship between lexical competence and language proficiency: variable sensitivity. SSLA, 27, 567-595.

Vermeer, A. (2001). Breadth and depth of vocabulary in relation to L1/L2 acquisition and frequency of input. Applied Psycholinguistics, 22, 217-254.

Waring, R. (2002). Scales of vocabulary knowledge in second language vocabulary assessment. Retrieved from www1.haranet.ne.jp/waring/papers/vocsize.html

Waring, R. (1997). A comparison of receptive and productive vocabulary sizes of some second language learners. Retrieved from www1.haranet.ne.jp/waring/papers/vocsize.html

Webb, S. (2005). Receptive and productive vocabulary learning: The effects of reading and writing on word knowledge. SSLA, 27, $33-52$. 